\title{
Editorial: OR for sustainable development
}

\section{Elise del Rosario ${ }^{1} \cdot$ Begoña Vitoriano ${ }^{2}(\mathbb{C}) \cdot$ Gerhard-Wilhelm Weber ${ }^{3,4}$ (1)}

Accepted: 7 September 2020 / Published online: 21 September 2020

(c) Springer-Verlag GmbH Germany, part of Springer Nature 2020

\begin{abstract}
The presented issue concerns publications presented as part of the Workshop 2018 of the EURO Working Group on Operational Research for Development (EWG-ORD) held in Complutense University of Madrid (Spain), July 5-7. This editorial presents an introduction on sustainable development and the Sustainable Development Goals. It contains short descriptions of the research area presented in individual publications, highlighting their contributions to the achievement of the Sustainable Development Goals.
\end{abstract}

\section{Introduction}

On the occasion of the EWG-ORD (Euro Working Group on OR for Development) 2018 Workshop-held in Madrid, Spain (July 5-7, 2018)-, the Central European Journal of Operations Research (CEJOR) invited submissions of papers to a special issue. The special issue focuses on theoretical, methodological and applied Operational Research contributions in improving the lives of people around the world.

EURO Working Group on Operational Research for Development (EWG-ORD) was established in 2006. Its aim is to promote and facilitate communication links among European and other researchers working in areas of operational research for development. EWG-ORD has been organizing yearly workshops to promote the importance

$凶$ Gerhard-Wilhelm Weber gerhard.weber@put.poznan.pl

Elise del Rosario elise@jgdelrosario.com

Begoña Vitoriano bvitoriano@mat.ucm.es

1 IFORS and EWG-ORD, OSSFFI, Eastwood, Bagumbayan, 1110 Quezon City, Metro Manila, Philippines

2 Interdisciplinary Mathematics Institute, Complutense University of Madrid, Madrid, Spain

3 Poznan University of Technology, Poznan, Poland

4 METU, Ankara, Turkey 
of operational research in improving the lives of people in developing and developed countries.

The EWG-ORD 2018 Workshop (https://www.euro-online.org/websites/ord/news/ news-item-0/) was a satellite event of the 29th European Conference on Operational Research held in Valencia, Spain (July 8-11, 2018). The Workshop held in the Faculty of Mathematical Sciences of Complutense University of Madrid, being the local organizer the research group UCM-HUMLOG Decision Aid Models for Logistics and Disaster Management (Humanitarian Logistics), by delegation of SEIO (Spanish Society of Statistics and Operational Research).

\section{Sustainable development and OR}

The United Nations Development Programme defines human development as "the process of enlarging people's choices," said choices allowing them to "lead a long and healthy life, to be educated, to enjoy a decent standard of living," as well as "political freedom, other guaranteed human rights and various ingredients of selfrespect." (UNDP 1997).

Development concerns expanding the choices people have, to lead lives that they value, and improving the human condition so that people have the chance to lead full lives (Streeten 1994). Development must be understood as the freedom of a person to choose leading to the kind of life they want with their decisions. Thus, human development is about much more than economic growth, which is only a means of enlarging people's choices. Fundamental to enlarging these choices is building human capabilities. The most basic capabilities for human development are to lead long and healthy lives, be knowledgeable (i.e., educated), have access to resources and social services needed for a decent standard of living, and be able to participate in the life of the community (UNDP 2009).

The Millennium Development Goals (MDGs) were established in 2000 by the United Nations for the period 2000-2015. With the aim of alleviating extreme poverty by 2015 , "the MDGs set timebound targets, by which progress in reducing income poverty, hunger, disease, lack of adequate shelter and exclusion - while promoting gender equality, health, education and environmental sustainability - can be measured. They also embody basic human rights - the rights of each person on the planet to health, education, shelter and security." (UN 2020a, b). Many of the MDGs, which were oriented for developing countries, were achieved. The number of people living in extreme poverty (defined as less than 1,9 \$/day) was reduced from 1.900 million in 1990 to 736 million in 2015. Nevertheless, currently, around half of world population (3.400 million) live with less than 5,50 \$/day, a number that has not changed since 1990.

The MDGs were followed in 2016 by the wider and much more ambitious Sustainable Development Goals (SDGs). Sustainable development is defined as development that "meets the needs of the present without compromising the ability of future generations to meet their own needs" (UNGA 1987). The SDGs are the blueprint to achieve a better and more sustainable future for all. Consisting of 17 goals to end poverty, protect the planet and ensure prosperity for all, SDGs affect all sectors in developing 
and developed countries. The 17 Goals are all interconnected, and in order to leave no one behind, it is important to achieve them all by 2030. (UN-SDGs 2020a, b). These goals are the following:

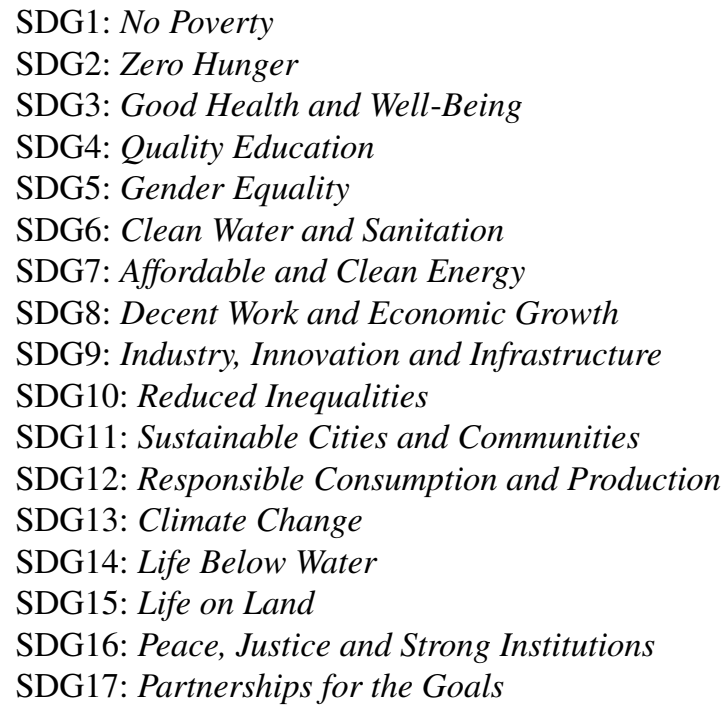

Present in many of these objectives, Disaster Risk Reduction is linked to sustainable development. Disaster risk reduction is the concept and practice of reducing risk through systematic efforts to analyse and reduce the causal factors of disasters. Examples of this type are reducing exposure to threats, reducing vulnerability of populations, rational management of the land and the environment, or improving preparedness of response to adverse events. For development activities to be sustainable they must also reduce disaster risk, and vice versa, weak development actions will increase risk and losses.

In 2020, this relation of development and disasters is explicitly shown. The pandemic COVID-19 is producing a health emergency while an economic emergency all over the world. Governments are putting in measures to protect health and life and manage severe economic recessions. Moreover, while the virus is affecting people regardless of their state in life, poor people are more strongly impacted. The virus has revealed a pre-existing pandemic of poverty (Alston 2020), which will be harder in next years. In https://www.un.org/sustainabledevelopment/ it can be seen how the pandemic is affecting the Sustainable Development Goals, in the description of each of them.

On the other hand, the military applications during World War II gave birth to Operational Research, the discipline that is now widely used to create better decisions thorough the use of advanced analytics and mathematics. Decision-making is a key component of the managerial function in various sectors of the economy and public services. OR should contribute to achieve the SDGs, incorporating consistent objectives with them, and contributing to establish policies and procedures. However, it may be said that the application of OR approaches to problems of Sustainable Development is still in its infancy. The articles included in this special issue are only a part 
of how much OR should collaborate to the achievement of the SDGs. OR involvement must be established as a priority for the coming difficult years, especially for the most vulnerable.

\section{Published research}

Based on very careful reviewing processes, 11 articles have been accepted for publication and became part of this exclusive collection of papers - our CEJOR Special " $O R$ for Sustainable Development”. It aims to showcase how OR is rising to the challenge of responding to decision-making and policy formulations to usher in a sustainable future.

The paper of Hans W. Ittmann on Lessons Gained from Four Case Studies of Operational Research for Sustainable Development in South Africa (Ittmann 2019) provides a perspective into the reasons why the application of OR in the area of sustainable development is not yet as far-ranging as it should be. The paper cites four case studies dealing with: setting up a community centre; sustainable village; service for HIV AIDS orphaned kids; and breastmilk bank. Using the following OR techniques, respectively: problem structuring, simulation, heuristics, and mathematical programming, the cases deal with various SDGs that addressed poverty, education, good health and well-being, among others. The projects were unsustainable largely due to funding and implementation issues. It is hoped that this documentation may be of help so that future OR projects will be more sustainable as it is applied to achieve the SDGs. WE can interpret this contribution as a continuation of the discussion on long-term load forecasting by Nalcaci et al. (2019).

Goal setting must be complemented by a system that monitors the journey towards the goals so that proper action may be taken when necessary. A methodology for doing this is proposed in Measuring Sustainable Development in the Education Area Using Multi-Criteria Methods: A Case Study (Roszkowska and Filipowicz-Chomko 2019). With education as one of the five key priority areas for the European Union, sustainability goals in education, SDG 4, which ensures inclusive and equitable quality education is studied. The SDG 4 indicators and their corresponding EU and national targets of the 28 member states are subjected to an extended non-compensatory TOPSIS procedure to generate composite indices. The countries were then ranked, taking into account the EU and their own respective national goals. The study enabled the use of a new methodology for measuring the level of implementation of the EU Strategy 2020 in education and how it varied among member countries, hopefully showing some areas for shifts in policy decisions.

Access to safe and effective medicines is one of the key components of SDG 3 on Good Health and Well Being. Accessibility to needed medication could be affected by stock outs). Stock-Out Severity Index (SSI): Tool for Evaluating Inequity in Drug Stock-Outs, Bhattacharya et al. (2019) successfully offers a framework for treating stock out not as an absolute quantity but in terms of its effect. The authors develop a measure for determining the severity of a stock out through the use of demographic determinants and risk factors. This study opens up new areas for research as well as 
ways by which limitations and sourcing of data needed for the methodology may be addressed.

On the other hand, access to energy has traditionally been one of the basic indicators of development and challenges of sourcing this are addressed by SDG 7. Green technologies count among them photovoltaic, wind power, hydrogen or biomass. The paper A Methodology for Designing Electrification Programs for Remote Areas (Leon et al. 2019) aims to provide a tool that could be used by the photovoltaic rural electrification (PVRE) programs commonly implemented in remote areas, especially in developing countries. Citing the unforeseen high costs of maintaining the system that cause private energy service companies to abandon these projects, the authors offer a way of estimating maintenance costs and fee-for-service rates through the use of a combined mixed integer linear programming and rule-based expert system methodology. The MILP is modelled after a well-documented instance and is used to simulate other cases to obtain a larger data set. The expert system, using classification tree and linear regression, is then used to estimate the maintenance cost. The project was applied for a Moroccan program. The approach could be applied to other such programs in other countries, provided that an understanding of the problem characteristics in a locality and initial data required are available for the MIP run.

Driven by the long-term climate goal to affect a substantial increase in the share of renewable energy in the global energy mix, Aided Design of Market Mechanisms for Electricity Clusters (Kaleta 2019) focuses on the needs of local community-based initiatives. Called energy clusters, these are small, distributed resources located close to energy consumers and which usually support green technologies. The author offers a decision support system framework for designing a market mechanism for an electrical energy cluster. The proposed ARchitecture for Market Systems (ARMS) seeks to tackle the entire problem from design and deployment to the maintenance phase by integrating suitable modelling methods into one framework. The use of some aspects of this system was illustrated with an example which also showed the various system components that require further research. The main contribution of the paper is to empower clusters by providing them a decision support system that considers energy generation and demand balancing, distribution and electric power marketing.

Development has for years been linked to economic growth included as SDG 8 (decent work and economic growth). The paper Oil Prices and Economic Activity in BRICS and G7 Countries (Kilic and Cankaya 2019), analyse the effect of changes in oil prices on the economies of the G7 countries (Germany, Canada, United States, France, Italy, Japan and United Kingdom) and on the emerging economies of BRICS (Brazil, Russia, India, China and South Africa). The study is focused on both short-run and long-run relationships, and on different indexes related to economic growth: gross domestic product, monetary aggregate, interest rate spread, consumer price index, real exchange rate. The findings illustrate how these indexes are affected by oil price shocks in the different countries and show a continuity of the discussion started by the paper by Grames et al. (2019).

Industry, Innovation and Infrastructure is the subject of SDG9. Innovations that would help fresh agricultural products to be viable for both producers and retailers in the face of the worsening effects of climate change on food supply are urgently needed. The paper Sustainability in Fresh Agricultural Product Supply Chain Based 
on Radio Frequency Identification under an Emergency (Yan et al. 2019) is offered as a solution in this direction. Through an example of salmon as a product, the proposed optimization methodology is applied to show that an RFID-assisted revenue-sharing contract between the manufacturer and retailer that is automatically adjusted with shifts in demand, reduces the cost pressure on the manufacturer, thus enabling it not only to ensure the quality and quantity of fresh agricultural products, but also to deal with rotten fresh products. Furthermore, although the profit of the whole supply chain is reduced under a demand disturbance, coordinating the profits and loss of each member ensures economic sustainability for the entire supply chain. To make this more useful in the long-term, several follow up studies are needed to deal with more levels in the supply chain as well as the variety of contract types.

In the same way that vertical cooperation has proven beneficial, "Assessing the Environmental Benefits of Horizontal Cooperation Using a Location-Inventory Model" (Hacardiaux and Trancrez 2019) shows the same to be true for horizontal cooperation. The contribution to sustainable goals is its look into the impact of cooperation on the reduction of both logistics costs and $\mathrm{CO}_{2}$ emission. The study concludes that cooperation among more partners characterized by low ordering costs, vehicle fleets with a large capacity and covering a vast distribution area is beneficial in terms of reduced logistics costs and carbon footprint. On the other hand, characteristics involving high facility opening cost and unit holding costs, along with high demand variability of the product, while benefiting from lower logistics costs, do not significantly impact $\mathrm{CO}_{2}$ emissions. Mathematical programming is used to determine the impact of the various variables and it would be interesting to have this implemented on an actual case.

Reducing carbon emissions is the object of SDG13. Measuring Carbon Performance for Sustainable Green Supply Chain Practices (Ali et al. 2020) investigates how far different sectors of a developing economy are able to manage green supply chains with respect to 4 aspects: green procurement, green logistics, green products and process designs, and regulatory frameworks. Applied to survey data from manufacturing organizations in a congested industrial region of India and validated with appropriate statistical tests, results suggest that implementation of green procurement, green process and product design, and a relatively small number of employees help the organizations achieve their emission control goals. However, regulatory frameworks and practices of green supply chains have been ignored or underutilized leading to negative carbon performance. The methodology could be replicated for other regions to suggest policies that need to be implemented. The results should be combined with ideas from Schröder et al. (2019).

Decreasing the level of carbon emission drives carbon pricing policies. Into the framework of SDG11 on Sustainable Cities and Communities, the paper Effectiveness of Carbon Pricing Policies for Promoting Urban Freight Electrification: Analysis of Last Mile Delivery in Madrid (Arroyo et al. 2019) uses OR to estimate the cost of owning and delivering goods using battery electric vehicles (BEVs). A mathematical programming model formulated to minimize the variable cost of energy and fixed cost of recharging is solved using heuristic methods. The paper concludes that carbon pricing is not an effective tool for promoting electric vehicles in the short term, largely due to the high acquisition cost of BEVs. However, the model, through simulations, proved useful in evaluating various recharging infrastructure options. The method- 
ology could be retrofitted for other cities and BEV applications given that last mile transport is the most favourable application for this type of vehicle.

A key issue also for sustainable cities and communities is waste management. Circular Economy Implementation in Waste Management Network Design Problem: A Case Study" (Hrabec et al. 2019) presents a new approach to support strategic decision-making in the area of municipal solid waste management. The primary goal is to minimize waste residues for landfilling by reducing waste production, increasing recycling and using the resultant residual waste for energy recovery. A two-stage integer non-linear model is proposed, where the first stage locates the waste treatment facilities, and the second determines waste allocation to processing and transportation. From this strategic first stage, the model goes to the operational level of the second stage that deals with the operational issues including uncertainty of waste production.

\section{Concluding remarks}

The eleven papers present the various ways in which the methodologies of Operations Research could bring us closer to the goals of sustainable development. These are a fraction of the papers submitted and presented during the workshop, but also as a continuity of other events by Geiger and Vetschera 2019 who organized a workshop of the GOR Working Group Decision Theory and Applications 2017 (Geiger and Vetschera 2019).

The reviewers provided invaluable comments that helped select the relevant ones, and for this, the Guest Editors are grateful. The Guest Editors hope that this issue will inspire other OR workers to contribute their skills to enrich this area so that the broad and interdependent sustainable development goals may be achieved for a better future for the economy, environment, and society.

\section{References}

Ali SS, Kaur R, Ersöz F, Altaf B, Basu A, Weber GW (2020) Measuring carbon performance for sustainable green supply chain practices: a developing country scenario. CEJOR. https://doi.org/10.1007/s1010 $0-020-00673-\mathrm{x}$

Alston P (2020) Covid-19 has revealed a pre-existing pandemic of poverty that benefits the rich. In: The Guardian, July 11th 2020. https://www.theguardian.com/global-development/2020/jul/11/covid-19has-revealed-a-pre-existing-pandemic-of-poverty-that-benefits-the-rich. (Accessed on 18 July 2020)

Arroyo JL, Felipe Á, Ortuño MT, Tirado G (2019) Effectiveness of carbon pricing policies for promoting urban freight electrification: analysis of last mile delivery in Madrid. CEJOR. https://doi.org/10.100 7/s10100-019-00627-y

Bhattacharya B, Lin L, Batta R, Ram PK (2019) Stock-out severity index: tool for evaluating inequity in drug stock-outs. CEJOR. https://doi.org/10.1007/s10100-019-00634-z

Development in South Africa. Central European Journal of Operations Research. https://doi.org/10.1007/ s10100-019-00644-X

Geiger MJ, Vetschera R (2019) Selected papers from the workshop of the GOR working group decision theory and applications 2017. Cent Eur J Oper Res 27:283-285. https://doi.org/10.1007/s10100-0180602-3

Grames J, Grass D, Kort PM et al (2019) Optimal investment and location decisions of a firm in a flood risk area using impulse control theory. Cent Eur J Oper Res 27:1051-1077. https://doi.org/10.1007/s1010 0-018-0532-0 
Hacardiaux T, Tancrez J (2019) Assessing the environmental benefits of horizontal cooperation using a location-inventory model. CEJOR. https://doi.org/10.1007/s10100-018-0599-7

Hrabec D, Kůdela J, Šomplák R, Nevrlý V, Popela P (2019) Circular economy implementation in waste management network design problem: a case study. CEJOR. https://doi.org/10.1007/s10100-019-006 $26-\mathrm{z}$

Itmann HW (2019) Lessons gained from four case studies of operational research for sustainable

Kaleta M (2019) Aided design of market mechanisms for electricity clusters. CEJOR. https://doi.org/10.1 007/s10100-019-00640-1

Kilic E, Cankaya S (2019) Oil prices and economic activity in BRICS and G7 countries. CEJOR. https:// doi.org/10.1007/s10100-019-00647-8

León J, Martín-Campo FJ, Ortuño MT, Vitoriano B, Carrasco LM, Narvarte L (2019) A methodology for designing electrification programs for remote areas. CEJOR. https://doi.org/10.1007/s10100-019-00 649-6

Nalcaci G, Özmen A, Weber GW (2019) Long-term load forecasting: models based on MARS, ANN and LR methods. Cent Eur J Oper Res 27:1033-1049. https://doi.org/10.1007/s10100-018-0531-1

Roszkowska E, Filipowicz-Chomko M (2019) Measuring sustainable development in the education area using multi-criteria methods: a case study. CEJOR. https://doi.org/10.1007/s10100-019-00641-0

Schröder T, Lauven L, Beyer B et al (2019) Using PROMETHEE to assess bioenergy pathways. Cent Eur J Oper Res 27:287-309. https://doi.org/10.1007/s10100-018-0590-3

Streeten P (1994) Human Development: means and Ends. Hum Dev 84(2):232-237

United Nations (2020) Millenium Development Goals. Background. https://www.un.org/millenniumgoals/ bkgd.shtml. (Accessed on 18th July 2020)

United Nations (2020) Sustainable development goals. https://www.un.org/sustainabledevelopment/. (Accessed on 18 July 2020)

United Nations Development Programme (UNDP) (1997). Human Development Report 1997, p 15. ISBN 978-0-19-511996-1

United Nations Development Programme (UNDP) (2009) Human Development Reports 2009

United Nations General Assembly (1987) Report of the world commission on environment and development: our common future. Transmitted to the general assembly as an annex to document A/42/427-Development and International Co-operation: Environment. http://www.un-documents.net/ wced-ocf.htm. (Accessed on 18th July 2020)

Yan B, Chen X, Yuan Q et al (2019) Sustainability in fresh agricultural product supply chain based on radio frequency identification under an emergency. Central Eur J Oper Res. 5:10. https://doi.org/10.1007/ s10100-019-00657-6

Publisher's Note Springer Nature remains neutral with regard to jurisdictional claims in published maps and institutional affiliations. 